TAO, Vol. 11, No. 2, 515-524, June 2000

\title{
Velocity Dispersion and Amplitude Attenuation of Rayleigh Waves Across the Philippine Sea
}

\author{
Guey-kuen $\mathrm{Yu}^{1}{ }^{1, *}$, Moon-Tsu Tsai ${ }^{1}$ and Ruey-Der Hwang ${ }^{1}$ \\ (Manuscript received 1 May 1999, in final form 13 February 2000)
}

\begin{abstract}
The fundamental-mode interstation group and phase velocities and attenuation coefficients of Rayleigh waves along four paths across the Philippine Sea are determined to have periods of between 20 and 110 seconds by the two-station method. The values of group and phase velocities are quite consistent with the results of previous studies using the single-station method. Group and phase velocities vary significantly with different wavepaths at periods of less than 50 seconds, but for longer periods, the phase velocities are quite close. The inversion results show that the thickness of the lithosphere is about $60 \mathrm{~km}$ in the Philippine Sea, except in the area of the eastern volcanic islands where a slightly thinner lithosphere (about 50 km) is deduced. The attenuation coefficients observed in the Philippine Sea are higher than the values obtained in the Pacific. This result simply reflects that the Philippine Sea plate is younger than that of the Pacific. Lateral variation in attenuation coefficient is not as clear as it is in velocity because of its large variance. However, the vertical distribution of $Q_{\beta}^{-1}$ is quite similar to that for the shear velocity model.
\end{abstract}

(Key words: Rayleigh waves, Attenuation coefficients, $Q$ values, Shear velocity )

\section{INTRODUCTION}

In seismology, there are two approaches often used to study the structure of the Earth. One is to derive the velocity model from travel-time data and the other is to derive the Q model from attenuation observations. In the past, surface wave amplitude attenuations have been widely used to study the anelasticity properties of the crust and upper mantle (e.g., Mitchell, 1973, 1975; Mitchell et al., 1976; Yacoub and Mitchell, 1977; Canas and Mitchell, 1978; Hwang and Mitchell, 1986; Al-Khatib and Mitchell, 1991). These studies have also provided good results for regional velocity variations of the crust and upper mantle.

Previous studies in the Philippine Sea have devoted much effort to the determination of

\footnotetext{
${ }^{1}$ Institute of Geophysics, National Central University, Chung-Li, Taiwan , ROC

* Corresponding author address: Dr. Guey-Kuen Yu, institute of Geophysics, National Central University, Chung-Li, 320 Taiwan , ROC; E-mail: kuen@ses.gep.ncu.edu.tw
} 
velocity structure (e.g., Seekins and Teng, 1977; Yu, 1982; Yu and Chang, 1991; Oda and Senna, 1994), but none to amplitude attenuation. However, the Q structure, as derived from the attenuation observations, would provide us with some other important properties of the media which cannot be deduced from velocity data. In this study we try to determine the interstation amplitude attenuation, as well as velocity dispersions, of Rayleigh waves along four paths across the Philippine Sea using the two-station method.

\section{METHOD}

In this study, the two-station method was used to determine the interstation group and phase velocities and attenuation coefficients of Rayleigh waves at periods between 20 and 110 seconds. Although this method could eliminate errors coming from the source (e.g., mislocation of the source and uncertainties in origin time ), it requires each station pair to lie on the same great circle with the source and their records should also have high enough signal to noise ratio. In this case, there are few seismograms that meet these conditions. In order to get more data, a maximum deviation of $5^{\circ}$ in azimuths between each station pair is accepted.

The spectral amplitudes and group velocities of the fundamental Rayleigh waves at periods between 20 and 110 seconds are first determined by the multiple-filter method (Dziewonski et al., 1969) and then refined by frequency-variable filtering (Russell et al., 1988) for each seismogram. A frequency-domain Wiener filter (Taylor and Toksoz, 1982; Hwang and Mitchell, 1986) is applied to determine the interstation Green's function, $G(f)$, between the station pairs according to the relation

$$
G(f)=\frac{H(f)}{R(f)},
$$

where $\mathrm{H}(\mathrm{f})$ is the cross-correlation matrix between the input signal (at station 1) and output signal (at station 2), and R(f) is the auto-correlation matrix of the input signal. As stated by AlKhatib and Mitchell (1991), frequency-domain Wiener filtering guarantees the removal of random noise and provides more stable and accurate estimates of group and phase velocities and attenuation coefficients than other methods do.

From the Green's function, the interstation group and phase velocities are calculated from the group delay and phase spectra of the transfer functions (Taylor and Toksoz, 1982) using the following formula

$$
(f)=\frac{X_{2}-X_{1}}{t_{2}-t_{1}}
$$

and

$$
C(f)=\frac{f\left(X_{2}-X_{1}\right)}{f t_{0}+(\Phi(f) \pm N)},
$$

where $\mathrm{X}_{1}$ and $\mathrm{X}_{2}$ are epicentral distances in kilometers for stations 1 and 2, respectively, $\mathrm{t}_{1}$ and 
$t_{2}$ are arrival times, $t_{0}$ is the first time point of the Green's function, $\Phi(f)$ is the phase of the Green's function in cycles, and $\mathrm{N}$ is an integer which provides the reasonable phase velocities for periods longer than 60 seconds. The interstation attenuation coefficients are calculated using the formula (Hwang and Mitchell, 1986)

$$
\gamma(f)=-\ln |G(f)| \frac{\sqrt{\sin \Delta_{2} / \sin \Delta_{1}}}{X_{2}-X_{1}},
$$

where $\Delta_{1}$ and $\Delta_{2}$ are the epicentral distances in degrees for stations 1 and 2, respectively, and $G(f)$ is the interstation Green's function. The uncertainties in the measurements of phase and group velocities and attenuation coefficients have been discussed in detail by several authors (Forsyth, 1975; Kijko and Mitchell, 1983). Systematic errors may be caused by interference from other phases, incomplete separation of modes, or lateral refraction. Russell et al. (1988) showed that use of a phase-matched and frequency-variable filter will guarantee removal of the phase of interest mode and will minimize spectral distortions due to phase fluctuation. Other systematic errors, such as mislocation of the source and uncertainties in origin time, will be canceled by using the two-station method.

\section{RESULT AND DISCUSSION}

Thirteen events along four path-pairs, GUA-MAT(GUMO-MAJO), GUA-SHK, GUMOTATO, and GUA-DAV, across the Philippine Sea, have been selected to determine the fundamental Rayleigh wave interstation group and phase velocities and attenuation coefficients at the periods between 20 and 110 seconds (Table 1 and Fig. 1). The mean observed values and their standard deviations for each path are shown in Figs. 2, 3, and 6, respectively. Figs. 2 and 3 show that the group and phase velocities along the paths for GUA-MAT and GUMO-MAJO are significantly lower than those for the other paths, especially for the period range of less than 50 seconds. This significant path-dependent variation agrees with the lateral variation statements of previous studies (Yu and Chang,1991; Oda and Senna, 1994). By inversion of

Table 1. Earthquakes used in this study.

\begin{tabular}{|c|c|c|c|c|c|c|c|}
\hline Date & Origin & Time (UT) & Latitude $\left({ }^{\circ} \mathrm{N}\right)$ & Longitude $\left({ }^{\circ} \mathrm{E}\right)$ & $\operatorname{Depth}(\mathrm{km})$ & Ms & Path \\
\hline Apr. 161982 & 14 & 51.2 & $15.8 \mathrm{~S}$ & $173.0 \mathrm{~W}$ & 33 & 6.4 & GUMO - TATO \\
\hline May 231982 & 02 & $08 \quad 09.0$ & $3.4 \mathrm{~S}$ & $177.4 \mathrm{~W}$ & 33 & 6.1 & GUMO - TATO \\
\hline Nov. 161983 & 16 & 1300.1 & 19.4 N & $155.4 \mathrm{~W}$ & 12 & 6.7 & GUA - DAV \\
\hline Sep. $09 \quad 1985$ & 09 & $33 \quad 13.0$ & $6.5 \mathrm{~S}$ & 149.9 E & 19 & 5.3 & GUA - MAT \\
\hline Oct. $28 \quad 1985$ & 06 & $37 \quad 18.4$ & $3.7 \mathrm{~S}$ & $151.7 \mathrm{E}$ & 10 & 5.4 & GUA - SHK \\
\hline Oct. $14 \quad 1986$ & 16 & 10.7 & $5.1 \mathrm{~S}$ & $153.6 \mathrm{E}$ & 40 & 6.6 & GUA - SHK \\
\hline Oct. $24 \quad 1986$ & 02 & 46.4 & $5.6 \mathrm{~S}$ & $153.9 \mathrm{E}$ & 52 & 6.3 & GUA - SHK \\
\hline Mar. 041992 & 03 & $49 \quad 00.0$ & $2.6 \mathrm{~S}$ & $147.5 \mathrm{E}$ & 33 & 6.0 & GUMO - MAJO \\
\hline Nov. 051993 & 22 & $37 \quad 23.0$ & $2.7 \mathrm{~S}$ & $147.6 \mathrm{E}$ & 33. & 6.0 & GUMO - MAJO \\
\hline Dec. 141993 & 06 & $31 \quad 25.0$ & $19.5 \mathrm{~S}$ & $173.1 \mathrm{~W}$ & 33 & 6.2 & GUMO - TATO \\
\hline Sep. 231994 & 07 & 39.0 & $3.1 \mathrm{~S}$ & $148.6 \mathrm{E}$ & 33 & 6.0 & GUMO - MAJO \\
\hline Feb. $02 \quad 1995$ & 19 & $50 \quad 45.0$ & $6.2 \mathrm{~S}$ & $148.7 \mathrm{E}$ & 33 & 6.0 & GUMO - MAJO \\
\hline Apr. $07 \quad 1995$ & 22 & 58.0 & $15.2 \mathrm{~S}$ & $173.6 \mathrm{~W}$ & 33 & 7.9 & GUMO - TATO \\
\hline
\end{tabular}




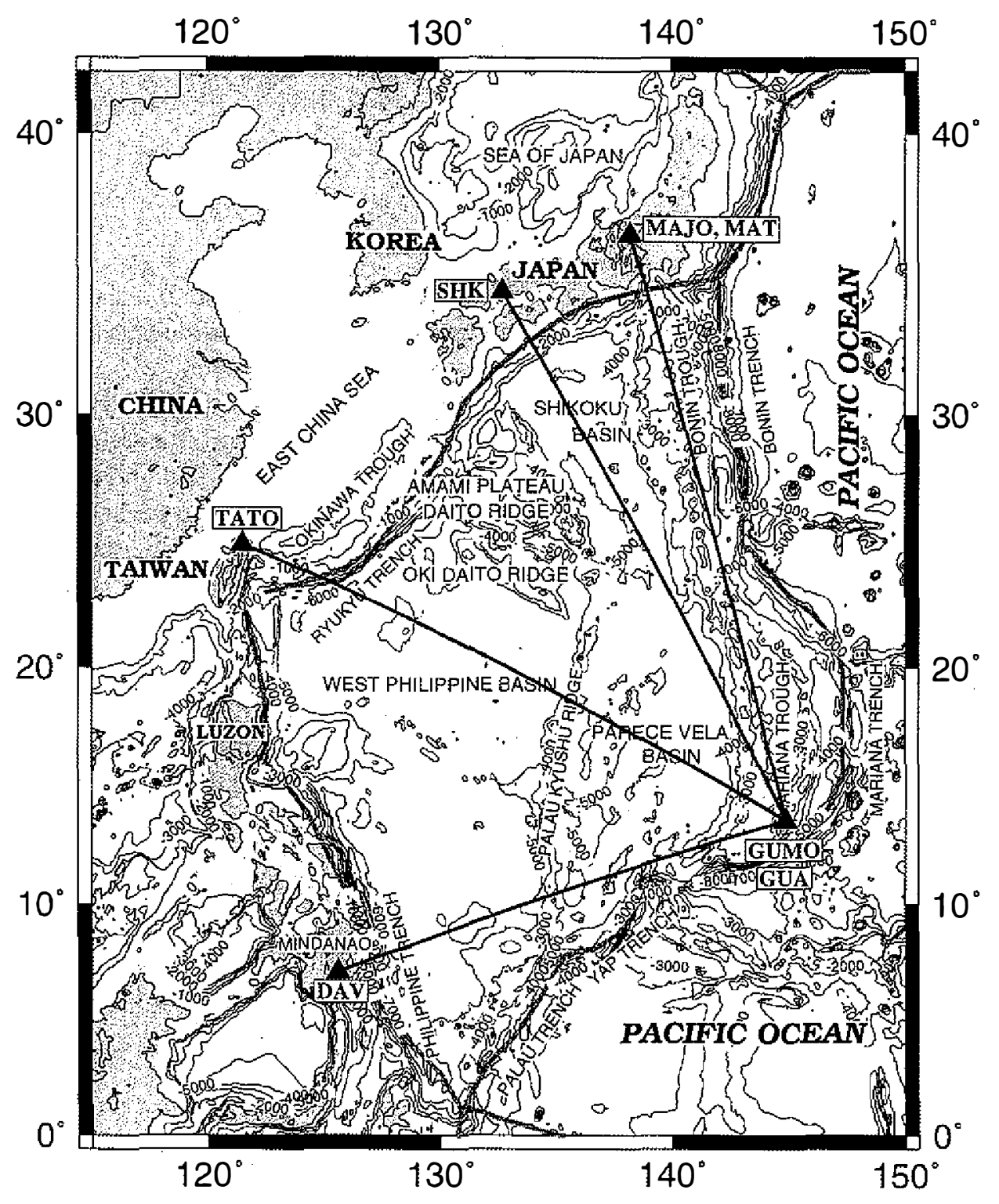

Fig. 1. Map showing the four paths of Rayleigh waves across the Philippine Sea. Triangles denote the seismograph stations.

the group and phase velocity data for each path, respectively, a lithosphere thickness of about $60 \mathrm{~km}$ is obtained for most parts of the Philippine Sea, except in the area of the eastern volcanic islands where a slightly thinner lithosphere thickness (about $50 \mathrm{~km}$ ) gives a better fit (Fig. 4). This result is different from the studies by Seekins and Teng (1977) and Yu and Chang (1991). However, the values of shear velocity, in our study, vary from 4.4 to $4.55 \mathrm{~km} / \mathrm{sec}$ in the lithosphere and from 4.1 to $4.3 \mathrm{~km} / \mathrm{sec}$ in the asthenosphere agree well with their results. 
Yu et al.

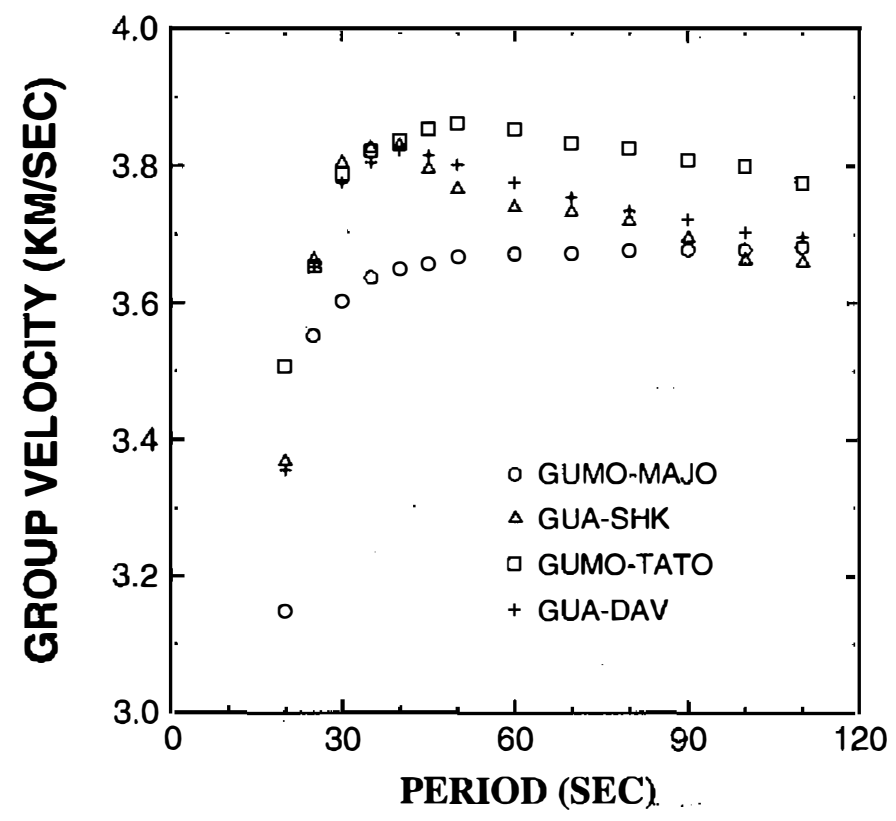

Fig. 2. Group velocity dispersion curves of the fundamental Rayleigh waves along four paths across the Philippine Sea.

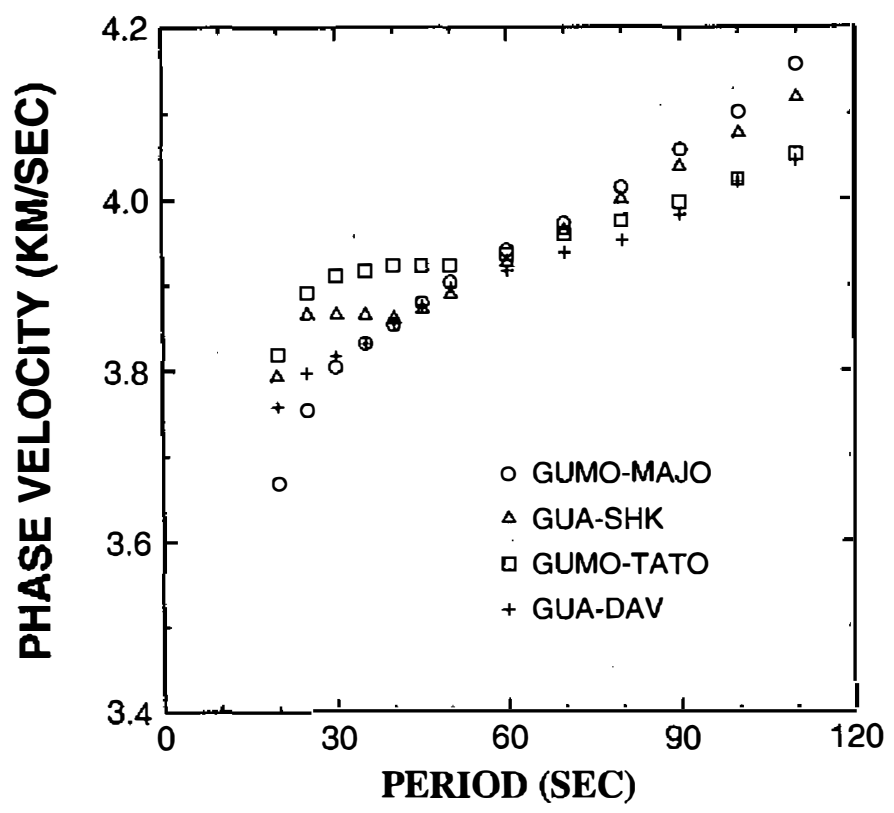

Fig. 3. Phase velocity dispersion curves of the fundamental Rayleigh waves along four paths across the Philippine Sea. 


\section{SHEAR WAVE VELOCITY (KM/SEC)}

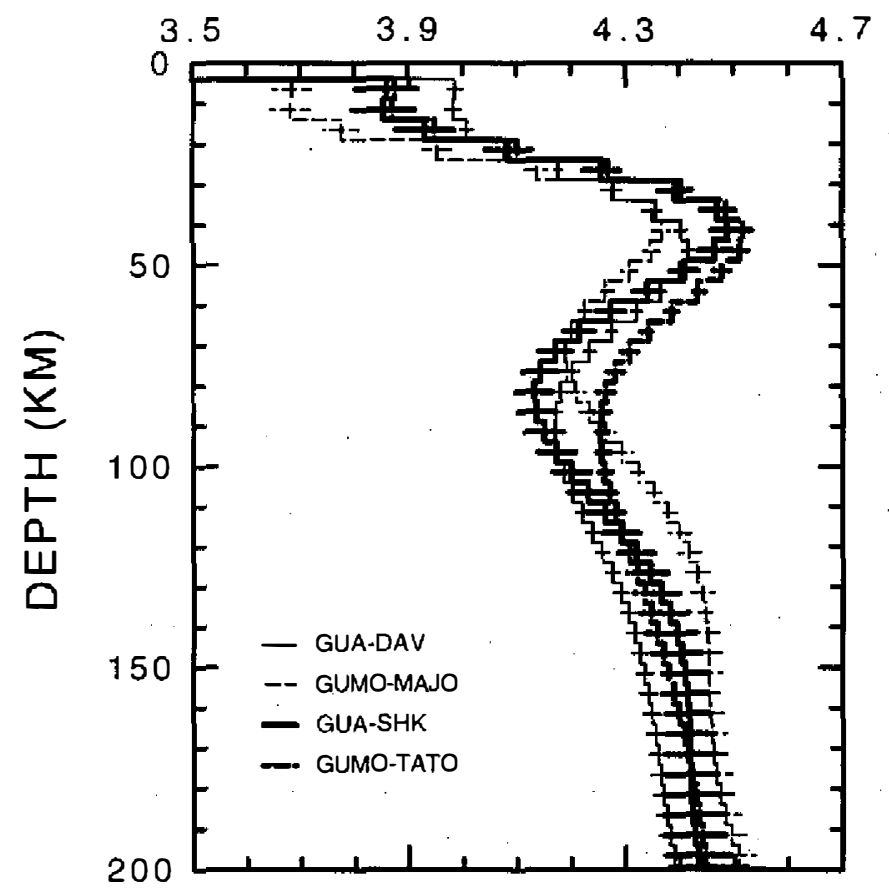

Fig. 4. Shear velocity models derived by inversion of the group and phase velocity dispersion data.

The Green's function of amplitude spectral ratio is plotted in Fig. 5 for each station-pair. Attenuation coefficients for each path are estimated from these spectral ratios and their values as well as their standard deviations are shown in Fig. 6. In this figure, some unrealistically high or low attenuation coefficient values occur at a few periods, and these may have been produced by different degrees of multiple arrival interference at one station compared to the other (Al-Khatib and Mitchell, 1991). Unreasonably small attenuations are observed along the paths crossing the eastern active island arc (GUA-MAT and GUMO-MAJO paths), where high heat flow and low velocities have been observed (Anderson, 1975; Seekins and Teng, 1977; Yu and Chang, 1991). Similarly, unexpected high attenuations at the periods between 36 and 70 seconds for the GUA-DAV path (Fig. 4) are also found. These unreasonable results may be affected by energy enhanced by multipathing interferences of wave propagation to stations MAT (or MAJO) and DAV, since these paths lie close to the plate boundary. Unfortunately, we cannot find more appropriate events for these paths. Moreover, low attenuation values observed at the periods between 24 and 40 seconds along several paths seem to need a high shear velocity layer at a shallow depth just below the Moho, but according to the velocity dispersion inversion result, there is no such high shear velocity layer at a shallow depth. Thus the model derived from velocity dispersion data is more reliable than that from attenuation values because we can measure velocity more accurately. 


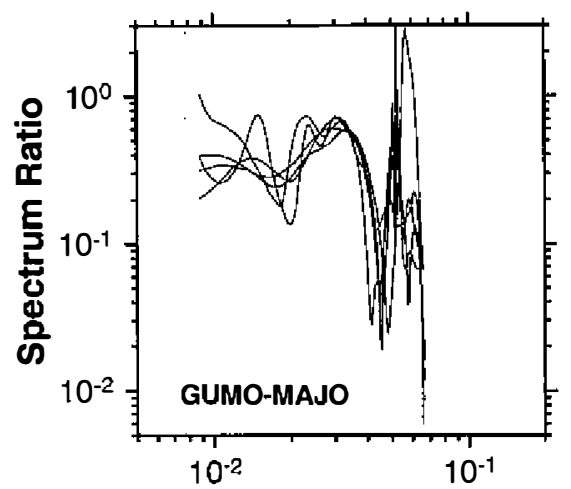

Frequency $(\mathbf{H z})$

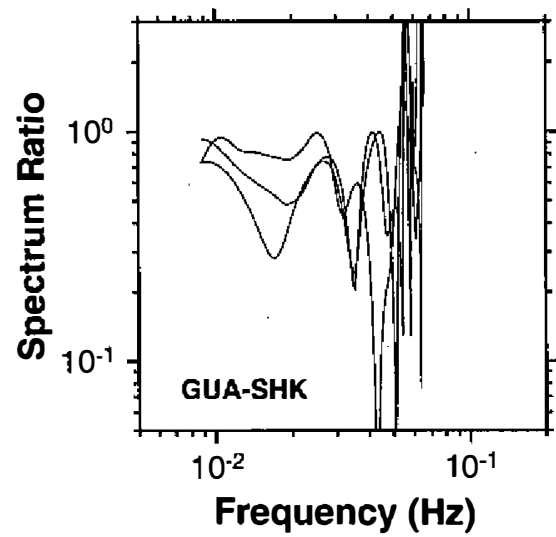

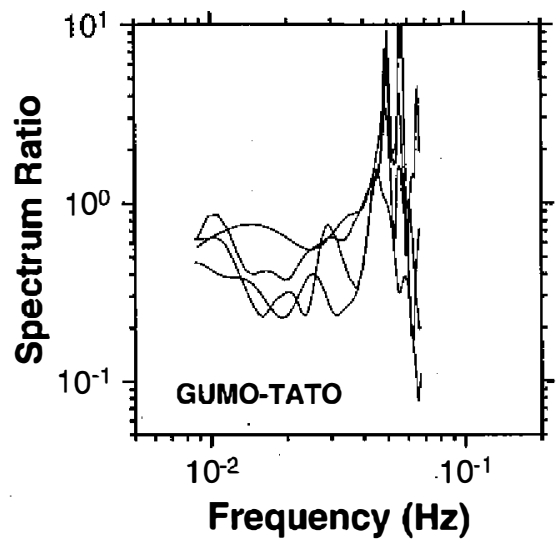

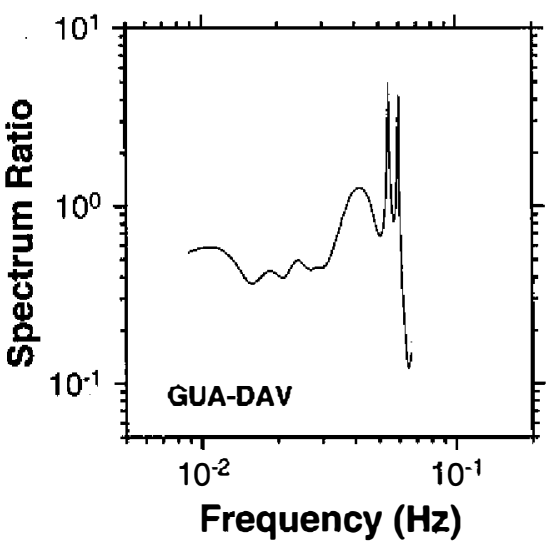

Fig. 5. The Green's function of amplitude spectral ratio for the four station pairs.

Figure 7 shows the vertical distribution of $Q_{\beta}^{-1}$ along each path. These distribution patterns match well with the velocity distributions. The average $Q$ values in the Philippine Sea are about 200 for the lithosphere and about 30 for the asthenosphere, respectively. These values are lower than the observations in the Pacific (Mitchell et al., 1976; Canas and Mitchell, 1977). This fact reflects the younger age of the plate and softer asthenosphere of the Philippine Sea compared to the Pacific (Seekins and Teng, 1977; Seno and Maruyama, 1984; Yu and Chang, 1991; Oda and Senna,1994). The average attenuation coefficients as well as their standard deviations of Rayleigh waves across the Philippine Sea are shown in Fig. 8. Also shown is the comparison with observations in the Eurasia and Pacific plates.

\section{CONCLUSIONS}

After analysis of the interstation group and phase velocities and attenuation coefficients along four paths of Rayleigh waves across the Philippine Sea using the two-station method, a number conclusions can be drawn. 


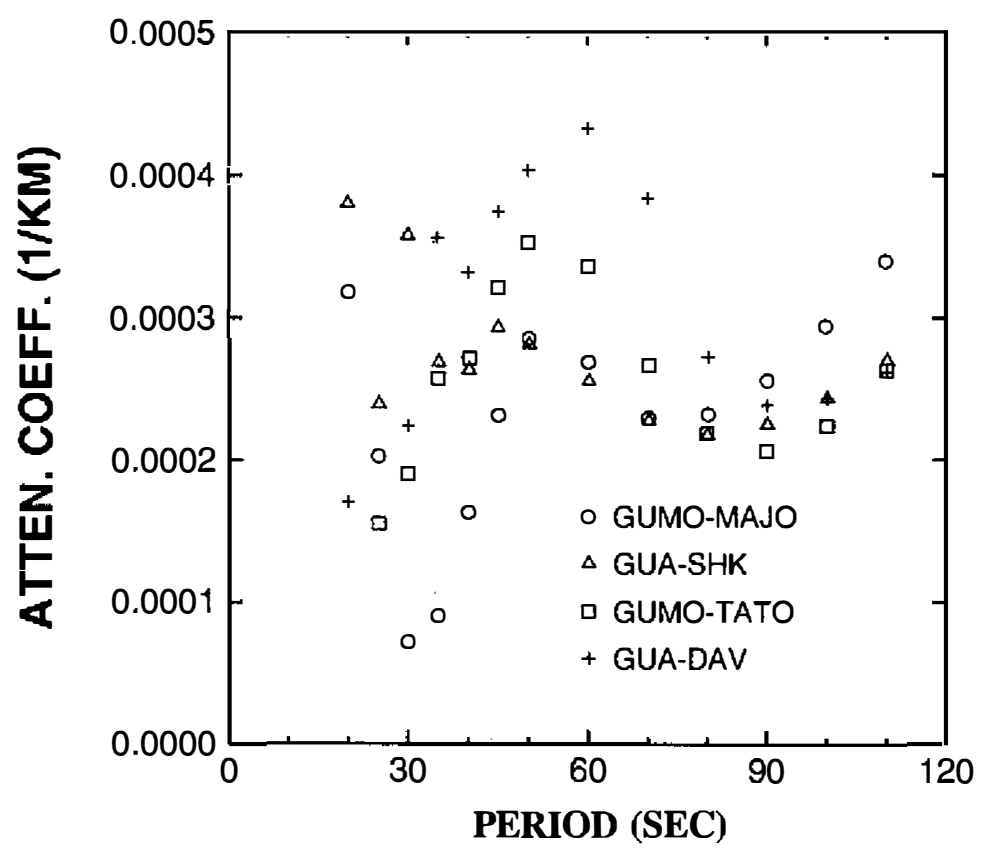

Fig. 6. Attenuation coefficients of the fundamental Rayleigh waves along four paths across the Philippine Sea.

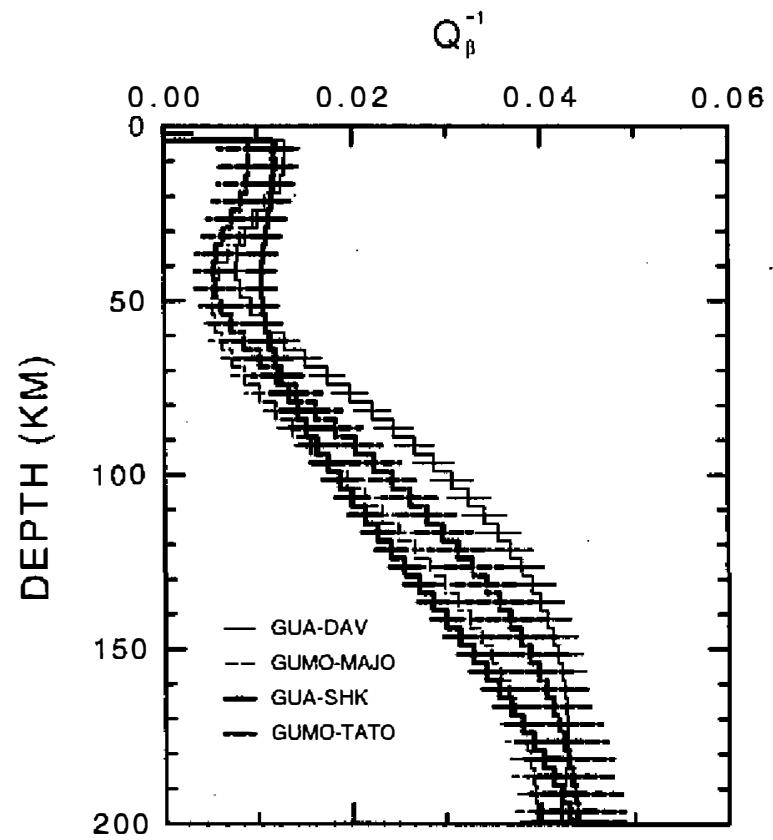

Fig. 7. $Q_{\beta}^{-1}$ models derived by inversion of the attenuation data. 


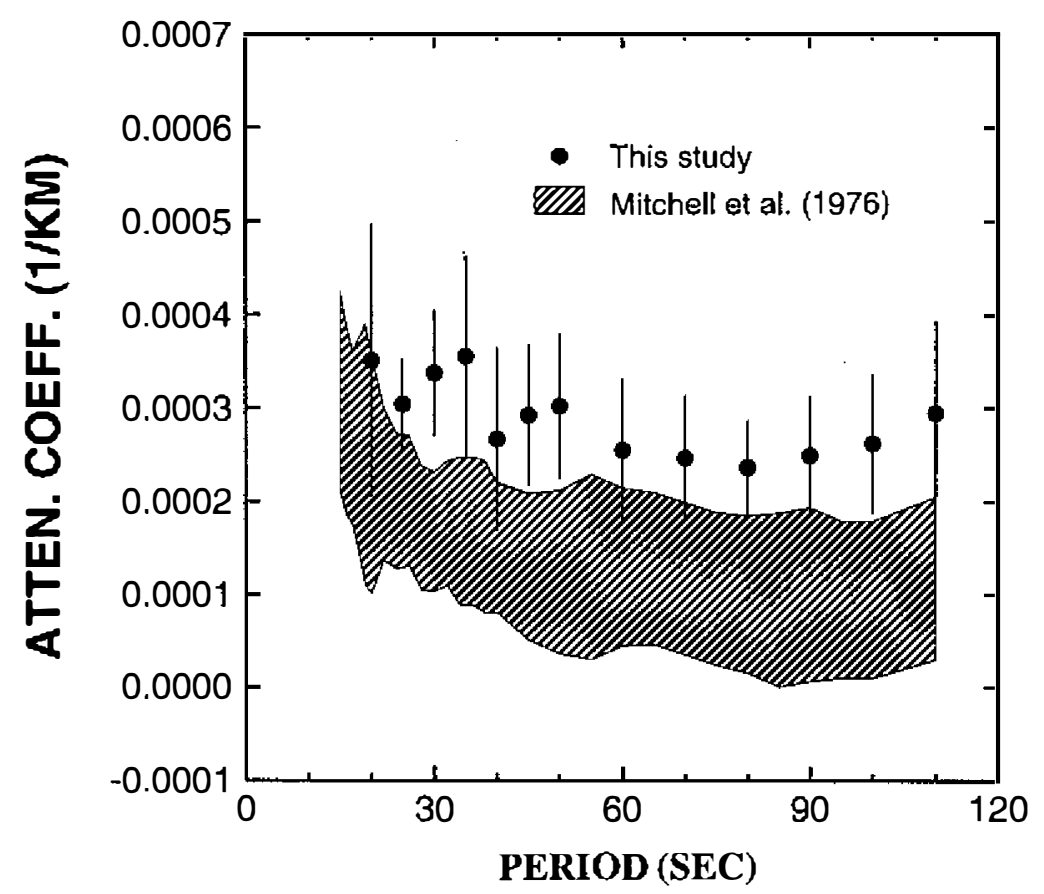

Fig. 8. The average attenuation coefficients and their standard deviations obtained for the fundamental Rayleigh waves obtained in this study compared with observations made in the Pacific (Mitchell et al., 1976) and in Eurasia (Yacoub and Mitchell, 1977).

(1) The thickness of the Philippine Sea plate is about $60 \mathrm{~km}$, except in the area of the eastern volcanic islands where $50 \mathrm{~km}$ is more likely.

(2) Shear velocities vary from 4.4 to $4.55 \mathrm{~km} / \mathrm{sec}$ in the lithosphere and from 4.1 to $4.3 \mathrm{~km} / \mathrm{sec}$ in the asthenosphere of the Philippine Sea.

(3) Attenuation coefficients observed in the Philippine Sea are higher than those obtained in the Pacific, but lower than the observations in Eurasia. In the Philippine Sea, the average Q values are about 200 for the lithosphere and 30 for the asthenosphere, respectively. Lateral variation in attenuation is not as clear as the velocity because of the large variance.

Acknowledgements This study was supported by the National Science Council, ROC under Grants No. NSC 84-2111-M-008-003 and NSC 85-2111-M-008-028.

\section{REFERENCES}

Al-Khatib, H. H., and B. J. Mitchell, 1991: Upper mantle anelasticity and tectonic evolution of the westem United States from surface wave attenuation. J. Geophys. Res., 96, 1812918146. 
Anderson, R. N., 1975: Heat flow in the Mariana marginal basin. J. Geophys. Res., 80, 40434048.

Canas, J. A., and B. J. Mitchell, 1978: Lateral variation of surface-wave anelastic attenuation across the Pacific. Bull. Seism. Soc. Am., 68, 1637-1650.

Dziewonski, A., S. Bloch, and M. Landisman, 1969: A technique for the analysis of ransient seismic signals. Bull. Seism. Soc. Am., 59, 427-444.

Forsyth, D. A., 1975: The early structural evolution and anisotropy of the oceanic upper mantle. Geophys. J. R. astr. Soc., 43, 103-162.

Hwang, H. J., and B. J. Mitchell, 1986: Interstation surface wave analysis by frequency domain Wiener deconvolution and modal isolation. Bull. Seism. Soc. Am., 76, 847-864.

Kijko, A., and B. J. Mitchell, 1983: Multimode Rayleigh wave attenuation and $Q_{\beta}$ in the crust of the Barents shelf. J. Geophys. Res., 88, 3315-3328.

Mitchell, B. J., 1973: Surface-wave attenuation and crustal anelasticity in central North America. Bull. Seism. Soc. Am., 63, 1057-1071.

Mitchell, B. J., 1975: Regional Rayleigh wave attenuation in North America. J. Geophys. Res., 81, 4904-4916.

Mitchell, B. J., L. W. B. Leite, G. K. Yu, and R. B. Herrmann, 1976: Attenuation of Love and Rayleigh waves across the Pacific at periods between 15 and 110 seconds. Bull. Seism. Soc. Am., 66, 1189-1202.

Oda, H., and N. Senna, 1994: Regional variation in surface wave group velocities in the Philippine Sea. Tectonophysics, 233, 265-277.

Russell, D. R., R. B. Herrmann, and H. J. Hwang, 1988: Application of frequency variable filters to surface wave amplitude analysis. Bull. Seism. Soc. Am., 78, 339-354.

Seno, T., and S. Maruyama, 1984: Paleogeographic reconstruction and origin of the Philippine Sea. Tectonophysics, 102, 53-84.

Yacoub, N. K., and B. J. Mitchell, 1977: Attenuation of Rayleigh-wave amplitudes across Eurasia. Bull. Seism. Soc. Am., 67, 751-769.

Seekins, L. C., and T. L. Teng, 1977: Lateral variations in the structure of the Philippine Sea plate. J. Geophys. Res., 82, 317-324.

Taylor, S. R., and M. N. Toksoz, 1982: Measurement of interstation phase and group velocities and Q using Wiener filtering. Bull. Seism. Soc. Am., 72, 73-91.

Yu, G. K., 1982: Surface wave study of the Philippine Sea plate. Proc. Natl. Sci. Counc. $R O C(A), 6,21-33$.

Yu, G. K., and W. Y. Chang, 1991: Lateral variations in upper mantle structure of the Philippine Sea basin, TAO, 2, 281-296. 